\title{
Testimonio y verdad: un falso dilema. El caso de la prisión política en Chile
}

\author{
Testimony and Truth: A False Dilemma. The Case of Political Prison in Chile \\ Testemunho e verdade: um falso dilema. $O$ caso da prisão política no Chile
}

\section{José Santos Herceg}

instituto de estudios aVANzados (IDEA), uniVersidad De SANTIAGo De CHILE

Profesor e investigador del Instituto de Estudios Avanzados (IDEA),

Universidad de Santiago de Chile. Doctor en Filosofía en la

Universidad de Konstanz, Alemania. Es autor de Conflicto de

representaciones (FCE, 2010) y compilador de los libros $L a$

fenomenología y sus herejías (Ediciones Universidad Alberto Hurtado,

2004), Interculturalidad e integración. Desafíos pendientes para América

Latina (IDEA, Universidad de Santiago, 2007), y coeditor de Escritos

republicanos (LOM, 2011). Correo electrónico: santosherceg@gmail.com

\section{Artículo de reflexión}

Este trabajo forma parte de la investigación titulada "Campos prisioneros en Chile. Reconfiguración de los lugares y las subjetividades" (FONDECYT N. ${ }^{\circ} 1140200$ ).

Documento accesible en línea desde la siguiente dirección: http://revistas.javeriana.edu.co

doi:10.11144/Javeriana.CL18-36.tvfd 


\section{Resumen}

En el presente texto se intenta tomar parte en la discusión acerca de la "verdad" de los testimonios. Se alude a algunas razones por las cuales no tendría sentido desestimarlos a causa de su no-coincidencia con la realidad de los acontecimientos. Se sostiene que los testimonios tienen ciertas características que les son propias: su confección es eminentemente instrumental, su perspectiva fuertemente personal y subjetiva y su relato está claramente ficcionalizado y narrativizado. El hecho de que estas características no se oculten, sino que estén a la vista -incluso sus mismos autores aluden a ellas-, hace evidente que no es posible sostener simplemente que se trata de textos "falsos", pues respecto de ellos se puede plantear directamente una dicotomía entre ficción y realidad.

Palabras claves: ficcionalización; instrumentalización; narrativización; testimonio; verdad; América Latina

\section{Abstract}

In this text we try to take part in the discussion about the "truth" of testimonies. We make reference to several reasons why it would not make sense to dismiss them because they do not coincide with the reality of the events. We state that testimonies have several characteristics of their own: they are made in an eminently instrumental way; their view is highly personal and subjective, and its account is clearly fictionalized and narrativized. Because of the fact that these characteristics are not hidden, but are in plain view -even their authors make reference to them- it is evident that it is not possible to simply state that they are "false" texts, as we have the possibility to establish a dichotomy between fiction and reality from them.

Keywords: fictionalization; instrumentalization; narrativization; testimony; truth; Latin America

\section{Resumo}

No presente texto tenta-se tomar parte na discussão sobre a "verdade" dos testemunhos. Refere-se a algumas razoes pelas quais não teria sentido rejeitá-los pela sua não-coincidência com a realidade dos acontecimentos. Levanta-se que os testemunhos têm certas características que lhes são próprias: a sua construção é eminentemente instrumental, sua perspectiva fortemente pessoal e subjetiva e o seu relato está claramente ficcionalizado e narrativizado. $\mathrm{O}$ fato de estas características não estar ocultadas, senão à vista -mesmo seus próprios autores referem-se a elas-, faz evidente que não é possível suster simplesmente que trata de textos "falsos", pois em relação a eles pode-se colocar diretamente uma dicotomia entre ficção e realidade.

Palavras-chave: ficcionalização; instrumentalização; narrativização; testemunho; verdade; América Latina

RECIBIDO: 11 DE ENERO DE 2014. APROBADO: 21 DE FEBRERO DE 2014. DISPONIBLE EN LÍNEA: 30 DE JULIO DE 2014.

\section{Cómo citar este artículo:}

Santos Herceg, José. "Testimonio y verdad: un falso dilema. El caso de la prisión política en Chile". Cuadernos de Literatura 18.36 (2014): 184-210. http://dx.doi.org/10.11144/Javeriana.CL18-36.tvfd 
1. En América Latina la "narrativa testimonial" surge en los años 60 del siglo pasado (Beverley, "Anatomía" 10; Sklodowska, "Hacia una bibliografía"; Sklodowska, Testimonio hispano-americano) y su "canonización", según se ha dicho, tiene lugar en 1970, cuando se instaura la categoría de "testimonio" en el premio Casa de las Américas ${ }^{1}$. A partir de entonces, comienzan a aparecer en el continente una gran cantidad de escritos de este tipo. Según Beverley, habría una serie de "factores" que explicarían esta "repentina proliferación"; menciona entre ellos la importancia de los textos documentales para la cultura latinoamericana, la popularidad de las historias etnográficas (life history) que se desarrollaron en los años 50, la recepción de los textos de memorias del Che Guevara y la significación que se da en la "contracultura" de los 60 al testimonio oral como forma de catarsis o liberación personal ("Anatomía" 10-11). A esta enumeración es indispensable agregar como causa directa, en palabras de Bustos, que "el salto del testimonio al dominio público se produjo inicialmente bajo el signo de la denuncia de la maquinaria de brutalidad que envolvió la práctica del terrorismo de Estado" (11).

En Chile, por su parte, la situación es análoga a la del continente en general. Según Epple, el testimonio conforma allí una larga tradición que este autor persigue hasta los inicios de la República; no obstante, advierte que "la atención hacia el testimonio como género distintivo, susceptible de codificarse como una categoría literaria, se produce a comienzos de la década del setenta" y, más importante aún, que es "la experiencia del golpe militar la que activa el registro testimonial como un fenómeno cuantitativamente amplio e inusitado de producción textual, rearticulándolo como un modelo sui generis de escritura" (1147). Jaime Concha se refiere a este fenómeno como una "avalancha testimonial". En efecto, es un hecho que el género testimonial ha sido cultivado profusamente desde 1973 hasta hoy en Chile, aunque, como constata acertadamente Strejilevich, su difusión ha sido limitada (22).

El corpus que forman dichos testimonios no es solo enormemente amplio; además, en palabras de Epple nuevamente, es "altamente diversificado" (1147). Tal diversidad se manifiesta primeramente en la cuestión del tema que aborda; en efecto, hay testimonios en los que se da cuenta de muy diferentes tipos de experiencias: asuntos que van desde participación en eventos políticos, pasando por experiencias religiosas, hasta situaciones relativas a viajes, diferentes tipos de acontecimientos, etc. En esta oportunidad interesa observar solamente los testimonios en los que se hace alusión a experiencias relacionadas con la prisión

1 La novela del cubano Miguel Barnet Biografía de un cimarrón (1966) se utiliza, habitualmente, como hito fundacional del género. 
política durante la dictadura militar de Pinochet (1973-1990). La diversidad, no obstante, aun con este recorte temático, persiste, pues en estas narraciones de orden testimonial se dan multitud de formatos: grabaciones, transcripciones de dichas grabaciones, declaraciones judiciales, entrevistas, etc. Tendré a la vista, por esta vez, solamente las obras escritas de más largo aliento que se han publicado, con el amparo o no de un sello editorial, en la forma de libro.

Con estos recortes la diversidad, sin embargo, continúa siendo un tema, aunque se logra acotar un corpus que, de lo contrario, sería simplemente inabarcable. Con el objeto de subsanar este problema se puede recurrir a una distinción de Duchesne. Este autor hace ver acertadamente que hay dos formas básicas de producción de testimonios: "aquellas obras en las cuales el testigo escribe directamente su testimonio" y "aquellas donde un autor traduce a la escritura la versión oral de uno o más testigos" (155). Los del segundo tipo son los que han sido recogidos por terceros, quienes asumen la tarea de dar lugar al relato. Lo más habitual es que sean periodistas quienes redacten a partir de entrevistas. Es el caso, por ejemplo, de Romo: confesiones de un torturador, de Nancy Guzmán (2000), o el de Sobrevivir a un fusilamiento. Ocho historias reales, de Cherie Zalaquett, (2005), entre muchos otros. También está el caso de los antropólogos, como el testimonio recientemente aparecido de Rolando Álvarez titulado Papá no va a llegar porque está trabajando en el norte. Memorias y epistolario de un preso político comunista y su familia en Chile (2012), que pese a estar escrito en primera persona, al modo de los relatos de vida, se construyó, como se explica en el prólogo, con base en una serie de entrevistas hechas por Isadora Stuven Di Pede a Rolando Álvarez.

Están, por otra parte, los testimonios en que la "mediación" ha sido reducida a la más mínima expresión, pues quien relata-escribe es el mismo sujeto que tuvo la experiencia. Dado el tema que nos preocupa, serán estos los testimonios con los que trabajaremos en esta oportunidad. Con esto podría parecer que se ha acotado mucho el corpus; sin embargo, hay una gran cantidad de escritos testimoniales publicados por los exprisioneros en forma de libros. Entre los más conocidos y que son más comentados por los teóricos están las obras de Luz Arce (publicada en 1993), Andrés Aylwin (aparecida en 2003), Sergio Bitar (publicada en 1987, pero con múltiples reediciones), Luis Alberto Corvalán (de 1976 y reeditada en 2007), Alberto Gamboa (de 1984, reeditada en 2010), Miguel Lawner (de 1976 y 2004), Jorge Montealegre (de 2003), Patricio Rivas (de 2007, premio Consejo Nacional del Libro y la Lectura), Hernán Valdés (de 1978, con múltiples reediciones) y Marcia Merino (de 1993). Junto a estos textos, que son objeto de gran número de comentarios, de estudios y circulan, por lo tanto, entre los investigadores y en las librerías, existe, además, un corpus aún más voluminoso de 
obras testimoniales relativamente desconocidas, o tal vez ignoradas, por la crítica. Paradigmáticamente, amén de los testimonios reconocidos y considerados, hay más de medio centenar que son muy poco comentados y que son casi imposibles de encontrar, pues no circulan en las librerías². Más allá de constatar esta situación y sin pretensión alguna de explicarla, hay que tener presente, sin embargo, que entre sus causas se podrían mencionar las editoriales que están detrás de las publicaciones, las fechas de su publicación ${ }^{3}$, el hecho de que sus autores gocen o no de alguna fama o reconocimiento desde antes - sean escritores, políticos, etc.-, el que su publicación desate alguna polémica, incluso escándalo, etc.

2. En la discusión teórica sobre el testimonio se han puesto de manifiesto una serie de problemáticas relacionadas con este tipo de discursos. Se trata, en efecto, de un campo de enormes controversias. Hay un ámbito problemático respecto de estos textos en el que quisiera detenerme en esta oportunidad: su relación con la "verdad". Bustos ha hablado de la "dimensión verista" del testimonio, en cuanto que se pretende una suerte de "fidelidad" frente a los hechos (12). Algunos autores de testimonios - la mayoría de ellos- reivindican, en efecto, la "verdad" de lo que relatan. "Quiso este libro", escribe Quinteros al iniciar

2 Habría que incluir aquí, por ejemplo, los testimonios de Freddy Alonso Oyanedel, Rolando Álvarez, Andrés Aylwin, Nubia Becker (Carmen Rojas), Mario Benavente, Ernesto Carmona, Rolando Carrasco, Juan Casassus, Carlos Cerda, Luis Alberto Corvalán, Adolfo Cozzi, Claudio Durán, Virgilio Figueroa, Alberto Gamboa, Juan Carlos García, Manuel Guerrero, Enrique Jenkin, Sadi Joui Joui, Miguel Lawner, Carlos Lira, Jorge Montes, Guillermo Núñez, Ángel Parra, M. Pinto, Haroldo Quintero, A. Quijada, Francisco Reyes, Patricio Rivas, E. Rojas, Rodrigo Rojas y otros, Rodrigo Rojas, P. Santelices, G. Teillier, Juan del Valle, Sergio Villegas, Sergio Vuskovic, Alejandro Witker, Sergio Zamora, etc.

3 Si se observa la aparición de los testimonios en relación con sus años de publicación, los resultados son interesantes. Tomando un listado de 62 testimonios escritos por autores-protagonistas, atendiendo al año de publicación de su primera edición, resulta que todavía durante los años 70 y luego del golpe de Estado - entre 1974 y 1979- se publicaron 18 testimonios —-todos ellos, por supuesto, fuera de Chile—, mientras que en la década siguiente (1980-1989) tan solo aparecieron ocho. Hay que destacar que en esta década hay seis años en los que no hay registro de que haya aparecido testimonio alguno $(1980,1982,1983,1985,1986,1988)$. Esto podría leerse, sin casi dificultad, como una consecuencia del recrudecimiento de la represión violenta en Chile. Los años 90, sin embargo, no presentan un panorama mucho mejor, ya que el promedio en ellos es de un testimonio por año, diez en total. Esto sorprende, aunque quizás no tanto, si se considera que en esta década el país había "retornado" a la democracia. A partir del año 2000, sin embargo, se puede percibir un claro repunte, pues desde entonces aparecieron veintiún testimonios: cada año aparece al menos uno, incluso hay cinco en el 2003 y cuatro en el 2004. Los años que van corridos desde el 2010 auguran que esta tendencia podría mantenerse, aunque algo atenuada, pues en tan solo tres años ya se han publicado al menos cinco testimonios. 
su testimonio, "alcanzar los lindes de la verdadera y vivida realidad" (12). "Todo lo que aquí se relata ocurrió" son las escuetas y contundentes palabras con que se abren las "Advertencias" del texto de Sergio Vuskovic (9). Sin ir más lejos, entre las finalidades más habituales de los testimoniantes están, como veremos, la de corregir la Historia y, por lo tanto, la de instalar la verdad acerca de unos acontecimientos que no se conocen o se conocen erróneamente.

Con esta pretensión de verdad se abre una de las mayores fuentes de debate acerca de los testimonios. Se trata del problema de la interesante relación que en ellos se da entre la ficción y la realidad: son textos que no pueden ser considerados ni un cuento, ni un reflejo de la realidad y, sin embargo, tienen, como han dicho los críticos, algo de ambas (Amar Sánchez 447; Beverley, "Anatomía" 9; Sklodowska, Testimonio hispano-americano 379). El problema que se plantea puntualmente es el de la sospecha acerca de la "veracidad" de un testimonio, a raíz de que la información allí contenida no "coincidiría" con la verdad de los hechos. Beverley alude, a modo de ejemplo, al caso del antropólogo David Stoll, que, habiendo vivido un año en las tierras del pueblo de Rigoberta Menchú, afirma que lo que ella sostiene en su testimonio acerca de la muerte de su hermano es una "invención literaria", pues no coincide con los hechos ("El testimonio" 491). Con ello se pretende "desestimar" la versión de Rigoberta Menchú, desplazándola al ámbito de la invención literaria, de la simple ficción. Nora Strejilevich hace ver que, respecto de los testimonios, hay una serie de expectativas: "La sociedad quiere que sirvan de evidencia y se siente autorizada a condenar aquellos que no coinciden con ciertas pruebas logradas por otras vías. En este punto, sus limitaciones saltan a la vista y la palabra del testigo se transforma en falible, inadecuada" (10-11).

El objeto que se propone este trabajo es analizar algunas razones por las cuales no tendría sentido desestimar los testimonios por su no-coincidencia con la realidad de los hechos. Se sostendrá, como hipótesis, que en el caso de los testimonios no es posible plantear una dicotomía entre ficción y realidad, y que, por lo tanto, no sería razonable invalidarlos, desautorizarlos y desecharlos utilizando como argumento el que no dan cuenta de la verdad de lo acontecido. Para hacerlo se tendrá a la vista lo dicho respecto de los testimonios por parte de los críticos, pero sobre todo se atenderá a lo señalado por los mismos autores de los testimonios. Se prestará especial atención a los "paratextos": título de la obra, dedicatorias, notas y citas — cuando la hay—, epílogos y epígrafes, pero sobre todo a las autopresentaciones que incluyen los autores al comienzo de sus escritos. Es sintomático que en la casi totalidad de este tipo de textos exista un prólogo, una presentación, unas palabras preliminares, una introducción, una advertencia o algo análogo. Dichos apartados buscan explicar el contexto de redacción y dar 
indicaciones para una correcta comprensión del escrito. Ellos nos servirán como fundamento para sostener que, dadas sus características peculiares, la objeción de "falta de verdad" no es algo que tenga sentido esgrimir contra los testimonios.

3. La primera razón que analizaremos se vincula con el hecho de que los testimonios tienen un claro sentido instrumental: siempre se escribe para algo. Es razonable, en efecto, preguntarse qué es lo que lleva a un sujeto que ha pasado por una experiencia límite, tan dolorosa como lo son la prisión política, la tortura o el exilio, a escribir y publicar su testimonio. Norma Castillo decía que no es posible confesar la verdadera experiencia, esa experiencia profunda, la de lo que realmente ocurrió; ni siquiera es posible para uno mismo reconocerla, menos aún dar testimonio público de ella ${ }^{4}$. Hay en el testimoniar un exponerse y, con ello, un dar realidad concreta, tangible, visible a un acontecimiento que, en verdad, más bien se tiende a negar y, sin duda, se quisiera olvidar, borrar. "Nunca estuve dispuesto a mostrar este mapa íntimo. No sé si no lo hice por pudor o miedo. Tal vez solo fui incapaz de ordenar las imágenes en un relato. Hay situaciones que he querido olvidar, pero han abierto todas las puertas que les cierro" (Rivas 9). Caracterizaría al testimonio lo que René Jara llama "intimidad pública", en cuanto que se transgrede del todo el límite entre lo público y lo privado. Si el testimonio es un exhibir en el domino público una intimidad desgarrada, no cabe duda de que es pertinente preguntarse qué es lo que mueve a un sujeto a incurrir en ese nivel de exposición.

En la crítica se ha hecho hincapié en el hecho de que, en un testimonio, la unidad suele ser una "vida" o una "vivencia particular significativa" y en que el relato siempre involucra para el narrador una cierta "urgencia" o "necesidad de comunicación" dada la magnitud o radicalidad de la experiencia (Beverley, "Anatomía" 9; Beverley, "El testimonio" 490; Bustos 11-12). Sergio Bitar, refiriéndose al modo en que produce su testimonio, alude concretamente a esta urgencia: "Había pasado por una experiencia que jamás imaginé podía darse en mi patria, y después de ella sentí el imperativo, la necesidad de transmitir esa vivencia" (15). Escribe Haroldo Quinteros, en el prefacio de su testimonio, algo en el mismo sentido: "Poco tiempo después de mi llegada a Bélgica, en calidad de refugiado político, me pongo a ordenar las páginas que vienen. Cuando las escribía no pensé jamás que podían transformarse en este libro. Las escribí, porque quise hacerlo con toda mi alma" (17).

4 Esto fue dicho en el contexto del coloquio organizado por el Instituto de Estudios Avanzados de la USACH para la celebración de los cincuenta años de labor docente de Ana Pizarro, donde se presentó una primera versión de este trabajo (2,3 y 4 de octubre de 2013). 
$\mathrm{Al}$ margen de esta urgencia o apremio por dar testimonio, los testimoniantes casi siempre sienten la necesidad de dar cuenta, expresamente, de las razones por las cueles escriben. Esto distingue a este tipo de escritos de cualquier otro de orden exclusivamente literario. Se encuentran en las primeras páginas de esos relatos frases como "El propósito de este relato es [...]" (Alonso Oyanedel 11), "Estas páginas tienen como objeto [...]" (Villegas 7), "escribo estas palabras para que $[\ldots]$ ". o expresiones análogas. El hecho de que un testimonio siempre se escriba para algo da cuenta de su sentido claramente instrumental. No se trata de textos que se agoten en sí mismos, sino que están allí con la finalidad de servir en la consecución de un determinado objetivo. Hay en ellos, por lo tanto, un "interés" que mueve a su realización. Dicho interés se materializa en la declaración expresa de ciertas finalidades.

Los teóricos del testimonio mencionan múltiples finalidades que serían perseguidas por esta clase de textos. La gran mayoría de tales finalidades transcienden el ámbito propio de la literatura, lo que ha sido ya constatado en múltiples oportunidades (Beverley, "El testimonio"; García V.), y se desplazan hacia otros territorios. Resulta interesante, además, contrastar las diferentes finalidades que, según sostienen los teóricos, movilizan a los testimoniantes con los dichos de los autores mismos. De acuerdo con estos últimos, los objetivos que los mueven a escribir son al menos de los siguientes órdenes: psicológicos, históricos, políticos y morales.

En el orden de lo psicológico son una multitud los objetivos que los autores traen a colación. Nora Strejilevich, que no solo es teórica, sino que además ella misma es autora de un testimonio, sostiene que de lo que se trata es de "sobrevivir" a una experiencia horrorosa, para poder confrontarla dándole un sentido (15). Para otros teóricos, como Rodríguez y García, el objetivo de los testimonios sería "resistir" (García V. 426; Rodríguez 115). Esto se podría ejemplificar con el caso de Luis Vitale, quien señala respecto de su texto que se trata de sobrevivir "durante" la experiencia límite de la prisión". Hay, por otra parte, una búsqueda de sanación. En la presentación escrita por los hijos de Rolando Álvarez se dice: "aunque parezca increíble, nosotros, la familia de Rolando Álvarez Araya, hemos terminado de conocer sus padecimientos post-golpe de Estado mediante la elaboración de este libro. Especie de sanación y pago de una deuda pendiente" (Álvarez 6).

"Este trabajo forma parte de uno de los momentos más difíciles de mi existencia. Lo he llegado a querer más que a otros de mis libros porque me ayudó a vivir en esa 'situación límite"' (Vitale 2). 
En tercer término, todavía en el ámbito de lo psicológico, en los testimonios se habla del descargo, del alivio, de la liberación como objetivos. Lo dice Sergio Bitar con todas sus letras: "cuando terminé de dictar esta crónica, después de recuperar mi libertad, sentí un enorme alivio, como si descargara un gran peso de mi espalda" (15). "Era necesario un libro más sobre las atrocidades de la dictadura?", se pregunta el Dr. Jenkin y se responde de inmediato: "Sí, en la medida que tu yo interior continúa golpeando a la puerta para dejar salir lo que durante años ha rondado, runruneando; ideas y recuerdos, de mi convulsionada cabecita" (19). El nombre que escoge Jorge Montealegre para titular su testimonio alude a las "frazadas" que los prisioneros tenían en el Estadio Nacional. La "frazada" es una metáfora que atraviesa todo el texto y sirve en el prólogo para explicar justamente la razón que lo mueve a escribir. El relato se abre con una evocación: "Estoy en la oscuridad, hincado, cubierto con una frazada. Tengo 19 años [...]" (13). Montealegre cierra las palabras preliminares volviendo sobre la metáfora, diciendo que "estoy viendo a ese chiquillo tratando de respirar bajo la frazada. Me ahoga su imagen, que es tan parecida a la de tantos que estuvieron con él. Que respiren. Que no se queden para siempre bajo la frazada" (15). Francisco Reyes comienza su texto señalando que el hecho de que se atreva a dar a conocer sus recuerdos "lo siento, antes que nada, como una liberación personal" (9).

En otro orden de cosas, un orden que podríamos llamar "preocupación por la historia", aparecen objetivos diferentes del testimonio. En primer término, por ejemplo, está lo que Epple señala cuando alude a que la finalidad del testimonio sería "documentar lo inédito" (1144). En efecto, para algunos autores se trata de "dejar constancia" para que no se pierda el recuerdo. Los hijos de Álvarez hacen ver en su presentación que "su deseo de que esta historia no se perdiera entre los retazos de la memoria familiar, lo decidió al fin a contar su versión de los hechos" (Álvarez 5). Quinteros también explica que "si hay algo que me interesa en la publicación de este libro, es que se conozca la personalidad y el ejemplo de los compañeros que conocí tan de cerca y que fueron asesinados, luego de sufrir tortura. [...] Esos jóvenes inmolados por sus ideales, no deben ser héroes desconocidos" (17).

No se trata, sin embargo, solo de dejar constancia o documentar lo ocurrido, sino sobre todo de "rescatar del olvido" o, como dice Rivas, "impedir el olvido" (9). Nubia Becker (Carmen Rojas) insiste en la presentación de su testimonio en el sentido de "rescate" que tiene su obra: pretende rescatar "a los hombres de carne y hueso, con reacciones humanas en situaciones límites" (7), "rescatar lo que pensaban: las discusiones, opiniones, dudas y reflexiones; las contradicciones y los debates", y "rescatar también, la resistencia de tantos hombres y mujeres que, 
a pesar del miedo, el hambre y la soledad resistían sin tregua, y sin claudicaciones defendían la libertad y la vida". De lo que se trata, según la autora, es de "ir escribiendo la historia [...] de las luchas y esperanzas del pueblo chileno, una historia fantástica, como lo es toda historia verdadera" (8). En sintonía con esta idea, Cozzi escribe en su Chacabuco: "han pasado 30 años y siento como deber imperioso evitar que el viento árido de la pampa se lleve al olvido todo aquello de lo que fui testigo" (9). Rivas lo dice expresamente: "la lucha por interpretar lo que nos sucedió es una manera modesta de impedir el olvido" (9).

Llevando las cosas un poco más lejos y trascendiendo la idea del rescate o la preservación, Yúdice habla de que la finalidad del testimonio sería "corregir la historia oficial" ("Testimonio and Posmodernism" 17) en cuanto que esta versión intentaría ocultar, tergiversar y justificar el olvido, manipular y provocar el desconocimiento. En este sentido, la finalidad sería poner de manifiesto la "verdad" que ha sido tapada, escondida. Mario Amorós, al referirse a su libro, señala por ejemplo que lo que buscaba era "demostrar que aquellos crímenes contra la humanidad no fueron 'excesos' individuales (como sostienen los defensores del tirano), sino el resultado de una política de exterminio decretada y planificada desde la cúspide del régimen" (6). "Quiso este libro", escribe Quinteros al iniciar su testimonio, "alcanzar los lindes de la verdadera y vivida realidad, que conmueven más que una noticia, por muy fuerte o infausta que esta sea. Esa fue, en suma, la razón más cardinal de su escritura" (12). Patricio Rivas, por su parte, establece lo siguiente: "mi memoria trabaja para que la caricatura que han dibujado sea reemplazada por la densa carga existencial de quienes vivimos los acontecimientos" (11).

Hay, por otra parte, un tercer tipo de finalidades de los testimonios que podríamos agrupar dentro del ámbito amplio de lo político. Algunos teóricos plantean que el testimonio tiene la enorme y nada humilde finalidad de cambiar el mundo, de transformar un pasado-presente de dolor (García V. 426). Por otra parte, están los que hablan de "hacer justicia" frente a las violaciones de todo tipo (Gómez Chávez 6o). Aylwin escribía en su testimonio: "en alguna medida ello era otra motivación que me ha interpelado a escribir, con la firme convicción de que la literatura es también una forma de hacer justicia, es decir, de condenar o reivindicar personas, tiempos e instituciones" (13). La idea de una lucha contra la injusticia aparece también como una finalidad habitual. Sergio Bitar confiesa: "me ha movido el amor a mi país, y me anima la defensa de la dignidad de cada hombre y mujer. No es posible avalar con el silencio, la injusticia y la tragedia que vivimos". "Es el deber de todos los chilenos evitar que se repitan los sucesos que aquí se relatan, para asegurar las libertades de todos" (17). 
En una línea muy cercana, pero posiblemente separable, está la idea de "denunciar" (García V. 426; Rodríguez 115), lo que se hace, sin duda, mediante una provocación de la opinión pública. En la nota preliminar para la edición de 1996 de su libro, Hernán Valdés, aludiendo al prólogo de la primera edición, declara que Tejas verdes fue escrito "sin otra pretensión que la de conmover la opinión pública sobre la situación chilena, que varios meses tras el golpe era prácticamente desconocida" (3). Dicha búsqueda de remover la opinión pública tiene para algunos la clara finalidad de motivar la lucha contra el fascismo ${ }^{6}$.

Dorfman agrega nuevos elementos teleológicos, elementos de orden moral, cuando señala que el testimonio sería "una forma de reiterar su superioridad ética frente al totalitarismo" (137). Montes lo dice con todas sus letras refiriéndose a lo que lo movió a escribir cuando todavía estaba en cautiverio: "Al escribir este libro, en papeles sueltos que mi mujer sacaba a manos seguras, desde cárceles y Campos de Concentración, quise mostrar el valor moral de los perseguidos, demócratas y revolucionarios, así como la ruindad fascista. Esta fue mi intención primigenia" (La luz 6). Esta denuncia de la "ruindad" moral de los carceleros y torturadores es lo que mueve a Alonso a escribir: "el propósito de este relato es explicar el porqué y de qué manera se desarrolló una suerte de morbosidad y sadismo a través de golpizas, flagelaciones, torturas y ejecuciones" (13).

Hay en el relato testimonial, como en cualquier relato de acontecimientos, una serie de decisiones que toma el autor: decide, por ejemplo, qué eventos relatar y cuáles callar, en qué orden y secuencia relatarlos, de qué forma hacerlo, etc. Las finalidades expresamente declaradas en los diferentes testimonios permiten hacer una lectura sobre estas decisiones, en cuanto que ellas sirven como criterio de selección y resolución. Se callan ciertos acontecimientos, pues su exposición podría atentar contra la finalidad política de denuncia o para que no sea dudable siquiera el carácter moralmente superior de las víctimas. Se organizan los hechos de cierta forma con el objetivo de provocar un efecto en el lector que lo mueva a apoyar la consecución de la finalidad que se persigue. Jorge Montealegre hablando de las "virtudes cotidianas", por ejemplo, alude a que ellas "se expresan en acciones y actitudes que, generalmente, no se declaran ni son objeto de preguntas porque son en apariencia banales; incluso 'enjuiciables' o reprochables por los propios sobrevivientes que públicamente evocan las vivencias funcionales a la

6 "Estas páginas son un testimonio de qué es el fascismo en la vida misma [...] Cuando lo escribía, rodeado de esbirros y bayonetas, intuía que pudiera servir de algo, y así creo que será: este librito justificará su existencia si alcanza, aunque ligeramente, a comprometer a más personas en la lucha contra el fascismo de nuestros días en donde este esté, si ayuda a fortalecer la solidaridad mundial [...] con la Resistencia Chilena y los combatientes chilenos" (Quinteros 12). 
denuncia, prioritariamente desde la memoria del horror, con sus recuerdos inevitables de privaciones y dolores" (Memorias 24).

Luis Villoro, refiriéndose a los historiadores, hace ver algo que es perfectamente aplicable al caso de los testimonios. Dice el filósofo que "es frecuente que los intereses particulares del historiador, ligados a su situación, dirijan intencionadamente la selección de los datos, la argumentación y la interpretación, a modo de demostrar la existencia de una situación pasada que satisfaga esos intereses" (41). El interés que estaría involucrado aquí es siempre un interés presente: no es el mismo el que estaba detrás de los primeros testimonios que el que anima los que se publican ya en el siglo XXI. Es lo que Le Goff llama "presentismo", en cuanto que existe una "influencia deformadora del presente sobre la lectura del pasado" (32). El interés por el pasado surge de un interés concreto por el presente. "Toda historia", dice Le Goff, "es contemporánea en la medida en que el pasado es captado desde el presente y responde a sus intereses. Esto no es solo inevitable, sino también legítimo" (52). Los testimoniantes están animados por un interés presente que guía su relato en cuanto a su contenido y su forma. Esto no implica, por supuesto, que dicho relato sea falso, que no se condiga con la realidad, sino simplemente que, al igual que cualquier relato de acontecimientos pasados, es una determinada interpretación, una cierta reconstrucción "personal" de dichos acontecimientos. Esto nos lleva a la segunda razón por la cual es posible considerar improcedente el desestimar los testimonios por no calzar exactamente con la realidad de los hechos.

4. Se ha hablado, en el caso de los testimonios, de una "desaparición del autor": cualquiera puede escribir un testimonio y no hay que resignarse a ser "representado" por otro. En palabras de Beverley, el testimonio "permite un acceso a la literatura a personas normalmente excluidas de ella" ("Anatomía" 12). Se trataría de la ausencia de pretensión literaria - pretensión de autoría- (Beverley, "El testimonio" 488), que le hace posible al testimonio otorgar "voz pública a quien carece de ella" (Bustos 11; García V. 426).

Hay testimonios escritos por sujetos con oficio, es decir, escritores profesionales. Es el caso, por ejemplo, de Tejas verdes (1978) de Hernán Valdés, quien al momento de escribir su testimonio ya había publicado algunas obras literarias, o de Jorge Montealegre y sus Frazadas del Estadio Nacional (2003), quien no solo ha publicado obras sino que ha ganado premios literarios ${ }^{7}$. En este grupo habría

7 Hay que observar, sin embargo, que Montealegre incluye en su testimonio textos que habían sido redactados a los diecinueve años mientras estaba preso, antes de comenzar a escribir sistemáticamente. De hecho, este autor comienza a escribir estando en Chacabuco. 
que mencionar también a Carlos Cerda (Pan de pascua), conocido fundamentalmente por sus obras de teatro pero escritor profesional, y a Adolfo Cozzi (Estadio Nacional). Junto a estos escritores literatos están también los que podríamos llamar escritores de oficio. Es el caso de periodistas como Alberto Gamboa, aunque él insista en que "no tiene ambiciones literarias" (14). En esta línea están también, por supuesto, Ibar Aibar Varas y Ernesto Carmona, entre otros. Sin duda, en este grupo podrían mencionarse igualmente los casos de los filósofos Sergio Vuskovic y Juan Casassus, así como el del historiador Luis Vitale.

Junto a estos autores experimentados en el arte o la técnica de escribir hay un grupo importante de testimonios que han sido redactados por sujetos sin oficio alguno de escritor. Se trata de autores de las más diversas profesiones. Luis Alberto Corvalán, por ejemplo, como se explica en el prólogo de su texto, es agrónomo, Patricio Guzmán es cineasta, Enrique Jenkin y Rolando Álvarez son médicos, Miguel Lawner es arquitecto, etc. Se podría decir, con certeza, que la gran mayoría de los testimonios han sido confeccionados por amateurs de la escritura, por sujetos que luego de escribir este texto, de hecho, no publicaron nada más, simplemente porque como dice expresamente Haroldo Quinteros "no soy escritor ni lo seré nunca" (17). Hay, en el esfuerzo de escribir de quien no lo hace habitual ni menos profesionalmente, un grado enorme de dificultad. Jenkin lo ve claramente al iniciar su testimonio: "No creo que resulte fácil para un cirujano que ha ejercido por más de medio siglo dedicado solamente a tratar de corregir fracturas, sanar esguinces y lo único que ha escrito durante toda la vida no han sido sino recetas y escuetas descripciones operatorias" (19). El ejercicio de escritura es para este doctor un "atrevimiento", una irreverencia (25).

A raíz de esta característica se puede decir, con Achugar, que en el caso de los testimonios se trataría de un "contradiscurso" frente a la elite intelectual que habría monopolizado el discurso narrativo (281). Gómez Chávez acentúa, en este sentido, su carácter "revolucionario" (61). De allí que la posible "crítica" a los textos, como literatura, en cuanto a su estilo, en general no preocupe a sus autores. Entre los testimonios hay una parte importante cuyo valor literario puede ser puesto en cuestión; sin embargo, ese no es el problema central aquí: los testimonios no son escritos como obras literarias; el serlo no está dentro de los objetivos declarados por sus autores. El "autor", en su calidad de "autor de una obra literaria", desaparece, ya sea porque quien escribe nunca lo ha sido ni lo será o porque aunque lo es, decide no escribir como tal. Quedaría desplazado el autor, quien cedería su lugar a un simple sujeto que pretende relatar su experiencia personal. Desaparecido el autor, como creador de una obra literaria, surge el autor del testimonio. Jorge Montealegre, en calidad escritor, da cuenta justamente de ello cuando habla de su 
tentación por completar, complementar, aliñar o incluso alterar el relato usando su imaginación literaria. "Me he resistido a novelar y a incorporar elementos de ficción. Tentaciones no me han faltado. Sin mayores pretensiones literarias, deseo que tenga el valor de un testimonio fidedigno" (15). Montealegre renuncia a ser "autor literario" para aparecer simplemente como sujeto que da su testimonio.

Este desplazamiento de lo que podríamos llamar "posición autoral" explica el que, como señala la crítica, en los testimonios, el acercamiento a los sucesos sea "personal", con el consecuente predominio de la primera persona gramatical (Amar Sánchez 449-450; Beverley, "Anatomía" 12). En el caso de los testimonios del primer tipo aludido por Duchesne, aquellos en que la mediación ha desaparecido, su carácter personal es evidente. Se trata de los testimonios dictados/ grabados o redactados directamente por el mismo sujeto que relata, en primera persona, sus experiencias. Andrés Aylwin publica en 2003 un texto en cuyo título está clara esta idea: el libro se llama Simplemente lo que vi. En este caso, el autor no pretende otra cosa más que dar cuenta de su perspectiva acerca de lo ocurrido. El título sugiere la adopción de una perspectiva neta y directamente subjetiva, como si dijera: "voy a relatar lo que yo vi y nada más que lo que vi". Al comenzar su texto inserta un apartado llamado "Una explicación" en el que establece que en su escrito "se trata tan solo de una narración de un conjunto de hechos, actuaciones, experiencias; una mirada hacia la realidad que me tocó ver y vivir en ese tiempo, en mi entorno inmediato" (11). Un poco más adelante, ahonda en este tema cuando constata que "al analizar los hechos en un espacio determinado, del cual, además, he sido parte integrante, resulta difícil separar debidamente la realidad objetiva, tangible, histórica, de mi apreciación subjetiva frente a ella" (14).

Alberto Gamboa, consciente de su mirada inevitablemente subjetiva y de la imposibilidad de imponerla, escribe: "no puedo decir enfáticamente: ¡Esta es mi verdad y la tuya no sirve!" (14), y Jorge Montealegre habla en su prólogo de su "opinable punto de vista" (Frazadas 15). Alonso Oyanedel, por su parte, comienza su testimonio con las siguientes palabras: "La verdad es que mi único anhelo es relatar desde mi perspectiva, los acontecimientos en Pisagua desde el 14 de septiembre de 1973 hasta el 30 de septiembre de 1974 " (11). Tan subjetiva es la perspectiva que Francisco Reyes advierte que "queriendo dar un testimonio personal hablo solo de aquellas cosas de las que he sido testigo o autor" (10). Es lo mismo que advierte Álvarez cuando señala que "trataré de no ser exagerado, no me siento un héroe de un pasaje histórico. Contaré exactamente lo que me tocó vivir, ni más ni menos" (15). 
En los testimonios, como bien lo saben sus autores, el acercamiento a los sucesos es "personal", ni objetivo ni menos científico. Como bien dice Bustos, "el testimonio lleva la impronta de un tipo de relato estructurado en primera persona, que daba cuenta de una experiencia apremiante, vivida en carne propia o en proximidad" (11). Dado su carácter expresa y confesadamente subjetivo, no tiene sentido exigirle al relato testimonial objetividad y tampoco exhaustividad en el recuento de los acontecimientos. Lo que se relata en un testimonio es la versión que de lo acontecido da uno de los implicados en los hechos: no dejará de mostrar su verdad, su visión, su perspectiva.

Enlazado con lo anterior, es importante tener a la vista que el testimonio es una "obra abierta", como la llama Beverley, pues "el narrador del testimonio es una persona real que continúa viviendo y actuando en una historia que también es real y también continúa" (Beverley, "Anatomía" 15). Hay, en el testimonio, una pluralidad de temporalidades: el tiempo de la experiencia, el tiempo del testimonio, el tiempo de la publicación. En algunas ocasiones estas temporalidades coinciden, pero lo habitual es que esto no ocurra. Por ejemplo, el tiempo de la experiencia coincide en algunos pocos casos con el del testimonio: en aquellos en que el autor escribe durante su prisión y luego lograr sacar los papeles y posteriormente publicarlos. Es el caso, por ejemplo, de Testigo presencial de Francisco Reyes $^{8}$, de Dawson de Sergio Vuskovic ${ }^{9}$ y de Diario de un preso político chileno de Haroldo Quinteros. Hay casos en los que existe un pequeño desfase temporal entre la experiencia, el relato y su publicación. Se trata de aquellos testimonios en los que se escribe o graba la experiencia inmediatamente después de obtener la libertad y se logra su publicación de inmediato en el extranjero, como consiguió hacerlo Hernán Valdés, por ejemplo.

Más habitual, sin embargo, es el caso de aquellas experiencias que se escriben inmediatamente después de la liberación del autor, pero cuya publicación se da con un desfase temporal. Es el de los que grabaron (Bitar 16), hicieron unos apuntes o redactaron algún texto (Montealegre) ${ }^{10}$ muy poco tiempo después de la experiencia, pero solo años más tarde retomaron la redacción del testimonio,

8 "Pronto se cumplirán treinta años desde que lo esencial de este libro fuera escrito en las cárceles de Chile y veinte desde que fuera editado por primera vez en la República del Ecuador" (Reyes 7).

9 El texto está dedicado, entre otros, "a los soldados, suboficiales y oficiales que ayudaron a salvar estos y otros apuntes, sacándolos de los distintos campos de concentración chilenos" (Vuskovic, Dawson).

10 Jorge Montealegre escribe sus experiencias en 1974, al ser recientemente liberado con diecinueve años, y vuelve a sus apuntes treinta años más tarde (Frazadas 15). 
cuando la vida ya había dado más vueltas. En este caso se pueden ver las tres temporalidades del todo disociadas y es la situación que más se observa. Allí es posible notar cómo la vida ha seguido su curso: los apuntes son modificados, alterados, suavizados, complementados, etc., para su publicación. Dichas alteraciones tienen que ver con el tiempo presente de la publicación. Cuenta Bitar, respecto del trabajo de edición de los textos, que "los revisamos conservando su espíritu original y su estilo de crónica. Si algún cambio mayor realizamos, fue reducir el tono apasionado, algunas expresiones cargadas de ineludible emotividad. Con el correr de los años, esa pasión se va desvaneciendo, para quedar con toda la fuerza, desnudos de adjetivos, los hechos mismos" (16). Montealegre toma decisiones diferentes y sobre la base de un manuscrito de 1976 construye un nuevo relato, pero retomando expresamente y sin alterarla aquella voz del prisionero de diecinueve años que había escrito recién puesto en libertad.

El último capítulo del libro de Nubia Becker lleva por título "Después de tantos años" y su contenido fundamental es una carta del año 1986, diez años después de la experiencia que da lugar al testimonio. La carta está dirigida a su pareja. Allí señala: "es que ya basta que nuestros mejores compañeros, los que son más necesarios e irremplazables; todos esos hombres y mujeres que hemos perdido, estén formando colección de libros-testimonio y galerías de héroes. $\mathrm{Me}$ niego a seguir inmortalizando a los nuestros, en posters, afiches, crónicas, aniversarios y... funerales!" (96). La vida debe continuar: ese es el mensaje de la carta, como si Becker se negara a seguir "estancada". La carta está escrita en primavera y la autora insiste en hablar de lo bellos que son los nuevos brotes de los árboles, de cómo el invierno va en retirada. "Felizmente ya pasó el invierno y empezará a disfrutar del sol y a desquitarse de sus fríos y de la humedad que le pone musgo a sus huesos" (96-97). En síntesis, señala la autora, "el tiempo no acaba de pasar y siguen las luchas, el amor... la vida. Y aquí estamos otra vez, escarbándonos por dentro para encontrar fuerza" (98).

Finalmente, está el caso de aquellos textos en los que coinciden el momento del testimonio y el de la publicación, pero lo hacen años después de transcurrida la experiencia que se relata. Esta es la situación en la que se hace más evidente el hecho de que el testimoniante ha seguido adelante con su vida y que dicha vida, por supuesto, afecta su testimonio. El momento de redacción es muy otro: otro es el contexto político, otras son las experiencias vividas por el autor, otra es la elaboración que se ha hecho de la experiencia que se relata, etc. Un caso especialmente significativo es el del libro Retorno a Dawson. Miguel Lawner, muy conocido por sus dibujos, publica el año 2004 este testimonio en dos partes y dos tiempos. La primera es un testimonio de los ocho meses que estuvo preso 
en Dawson entre los años 1973 y 1974, según su autor, escrito originalmente para complementar sus dibujos, pero que se autonomiza (11-124). La segunda es el relato de la visita que hizo a Dawson con un grupo de exprisioneros en 2003 (127-178). Entre la experiencia original de la prisión y la publicación de su relato median treinta años; el relato de la experiencia del retorno es casi inmediato.

Un autor que no es un verdadero "autor", una subjetividad desatada en una narración que es expresamente una versión "personal" de lo acontecido, un autor que se identifica con el personaje, que es el sujeto de la narración y que, por lo mismo, sigue viviendo, debe seguir haciéndolo entendiendo que dicha vida, a su vez, afecta la narración misma. La pregunta por su verdad, en cuanto "adecuación" con lo sucedido realmente, con los acontecimientos, por lo tanto, está fuera de lugar. En los testimonios, el acercamiento a los sucesos es "personal"; de allí que su objeto no sean los hechos, menos aún su secuencia ni su exactitud. Los propios testimoniantes reconocen que sería imposible pretenderlo. Dice Alonso Oyanedel: "Jamás se podrán olvidar sucesos tan horrorosos que se vivieron, pero la mente algunas veces no acompaña en recordar y revivir detalles de fechas, anécdotas y otras situaciones. Puede que haya algunos errores, por sentimientos, emociones, doy mis disculpas por ello; sin embargo, todo se mantiene en la verdad de lo ocurrido" (11).

Lo que interesa no son los hechos, los datos; lo que se relata es, más bien, el sentido de la experiencia" ${ }^{11}$. Patricio Rivas habla de que "al escribir se concentró en algunas imágenes cargadas de emotividad, no en sucesos lineales predecibles, inevitables" (8). De lo que se da cuenta en un testimonio de prisión política es del dolor, de la injusticia, del horror, no de las menudencias, ni de los detalles de cada lugar y acontecimiento. La verdad que busca el narrador no es la de una "adecuación" del relato con los hechos, por lo que, como bien dice Bustos, difícilmente podría imputarse a un testimonio un "error" (13). González escribe, al comenzar su testimonio: "No defiendo un sistema determinado, solo relato hechos, quizás haya algunos errores de tiempo, pero la historia no cambia" (12). Los errores no son lo importante para el testimoniante, ni deberían serlo para quien lo lee o interpreta. Si la constatación de errores tiene alguna relevancia es en la medida en que tales errores puedan ser un "síntoma"12.

\footnotetext{
11 "Lo cierto es que lo que apunté en este diario es real, y los sentimientos de mis compañeros presos y los míos, esencialmente reales, sentidos y vividos" (Quinteros 17).

12 Como dice Portelli, "las discrepancias y los errores son hechos en sí mismos, signos reveladores que remiten al tiempo del deseo y del dolor y a la difícil búsqueda de sentido" (27).
} 
5. De acuerdo con Beverley, el testimonio tiene la finalidad de relatar aquello que no pude ser representado adecuadamente por ninguna otra forma de escritura, pues de serlo, sería traicionado por estas ("El testimonio" 490). El testimonio sería el modo de expresión preferente - en realidad el único modo de expresión propio - de un determinado y particular tipo de experiencia. Tal vez su característica más notoria sea lo que se ha denominado narrativización o ficcionalización de figuras provenientes de lo real que pasan a constituirse en personajes y narradores. No hay nombres ni personajes, en los testimonios, que no aludan directa y expresamente a personas reales de carne y hueso. No hay invención de personajes, en el sentido de "ficciones". El protagonista de la historia y el de la experiencia se funden, y en aquellos testimonios escritos directamente por quienes vivieron la experiencia, se funden, además, con el autor. Solo en algunos casos, sobre todo por razones de seguridad, se han cambiado ciertos nombres, pero tan solo eso ${ }^{13}$.

Esta ficcionalización de las figuras reales no implica necesariamente un alejamiento completo de la realidad. Los testimoniantes no buscan escribir una obra de ficción. Ya se ha aludido antes a la resistencia de Jorge Montealegre a la tentación de completar, de complementar, de aliñar o incluso alterar el relato usando su "imaginación literaria" (Frazadas 15). Ruth González dice irónica y expresamente que "la semejanza de situaciones, personas, y lugares no son solo coincidencia" (12). Alude, claramente, a aquella advertencia que se lee al comenzar algunas películas en donde se señala, con el fin de evitar cualquier problema ulterior, que cualquier semejanza con la realidad es solo coincidencia. González acentúa que dicha semejanza es expresa, que es evidente, para destacar que se trata de la ficcionalización de una realidad con la que se corresponde ${ }^{14}$.

Pese a dicho propósito, el testimonio, al igual que cualquier narración de acontecimientos, es un relato; una producción oral o escrita sobre lo acontecido. Esta es una forma en la que se puede ver el gesto de los testimoniantes: como la "producción de un relato" que, como es evidente, no es ni puede ser la encarnación de lo ocurrido, sino tan solo lo que se cuenta acerca de lo que sucedió. Se podría decir del testimonio lo que Michel de Certeau ha escrito a propósito del texto histórico y de la labor del historiador: "La historiografía (es decir 'historia' y 'escritura') lleva inscrita en su nombre propio la paradoja - y casi el oxímoron-

13 Sergio Vuskovic comenta en sus "Advertencias" que "en resguardo de la seguridad de las personas, especialmente de los militares, se han cambiado u omitido ciertos nombres, grados y, en algunos casos, la secuencias de los días y las horas" (9).

14 Adolfo Cozzi escribe, en el mismo sentido, que "todos los hechos relatados ocurrieron verdaderamente y los protagonistas no son de ficción" (Chacabuco 9). 
de la relación de dos términos antinómicos: lo real y el discurso" (13). No resulta aventurado afirmar, por lo tanto, que los testimonios más que "reproducción" de la realidad de una experiencia son en realidad la "producción" de una versión posible de dicha experiencia. En este sentido señala Le Goff que "el pasado es una construcción y representación constante" (28). La verdad no es lo que se pone de manifiesto en la historia contada en los escritos testimoniales, sino lo que se produce mediante la escritura. Tal vez tendría sentido utilizar aquí el concepto de "hiperrealidad" de Baudrillard, en cuanto que el relato toma el lugar de la realidad, de la verdad de lo acontecido: suplanta los acontecimientos perdidos en el tiempo, en la medida en que pretendería ser más real que lo real. La verdad de lo ocurrido pasa a ser lo que se relata al respecto.

Patricio Rivas dedica un párrafo especial a lo que ha llamado "la artesanía de Chile, un largo septiembre" donde hace explícito el "método implícito" de la construcción de su relato. Señala allí que el escrito "no se rige por el formato del trabajo histórico tradicional o de la literatura en sentido estricto. Le gusta la mezcla" (9). Rivas explica el proceso de construcción con la metáfora de un álbum de fotos: "En un minucioso recuento puso las calles, las casas, los muebles, las personas, los aromas. Alteró nombres, aunque también reconoció algunos de sus combatientes. Revisó sus archivos y preguntó por fechas y situaciones. Describió procesos que luego borró porque no pudo encontrar a sus protagonistas" (9).

Una manifestación evidente y sorprendente de esta "producción" es la dialéctica extrañamiento/recuperación que se produce entre el autor y el testimonio. La anécdota que relata Bitar, cuando retoma en 1984 las trecientas páginas de la transcripción de las grabaciones que había hecho recientemente al ser liberado, grafica bien este tránsito de la experiencia al relato, del sujeto al personaje. Escribe Bitar: "releía las páginas y el recuerdo inicial era muy borroso, solo paulatinamente iba retornando a mi memoria. A ratos era como si el texto lo hubiera escrito otro" (16). De una experiencia análoga habla Jorge Montealegre: "Retomé los viejos escritos con una extraña sensación de releer mis recuerdos como descubriéndome a mí mismo" (Frazadas 15). En el texto de Montealegre conviven dos protagonistas y dos voces - una de 19 años y otra de 49- pero una sola persona que busca unificarse recuperando al joven. Parece posible hacer una lectura cuasi hegeliana de lo que ocurre con el testimonio: hay un movimiento de exteriorización (Entäusserung), extrañamiento/enajenación (Entfremdung) y posterior recuperación.

Un caso extremo, algo anómalo, pero especialmente interesante de analizar en el sentido de la ficcionalización como elemento esencial de los testimonios es el de Manos en la nuca (2005) de Ángel Parra. Se trata de un texto que parece estar a medio camino entre el testimonio y la novela: el protagonista de la narración es 
un jardinero, Rafael, claramente inventado por el autor, pero las vivencias que se relatan así como todos los otros personajes son tomados de la experiencia misma de este. Los personajes que participan en la acción son personas que existieron verdaderamente: se menciona a Gamboa El Gato $(33,99)$, Ibar Aibar El Chupao $(33,44,99,122)$, a Torres Gaona $(33,99)$, Manuel Cabieses $(33,43,50,99,122)$, Luis Alberto Corbalán (35, 41, 67, 83, 90, 122), Patricio Guzmán (43, 65), Marcelo Concha $(51,122)$, Rodrigo Rojas $(84)$, Carlos Naudon de la Sotta (99), Francisco Aedo (122) y el coronel Espinoza (89). En este caso, incluso el mismo Ángel Parra figura como un personaje de la obra $(36,41,65,122)$, participa de las anécdotas e incluso se habla en algunos pasajes expresamente de él. Todos estos personajes, que son también sujetos reales, son los que viven la experiencia del encierro en el estadio junto con Rafael. En la contratapa del libro se explica claramente la situación: "Ángel Parra [...] presenta una historia que él vivió en carne propia, recreándola por medio de un personaje".

La condición productiva y no meramente reproductiva de estos relatos testimoniales es algo que sus mismos autores tienen claro. Francisco Reyes, por ejemplo, advierte al comenzar a escribir que "los relatos no siempre están ordenados cronológicamente" y a modo de explicación señala que "mi única excusa es que los fantasmas fueron apareciendo y cobrando su lugar sin método ni control" (10). Incluso, este autor sabe que será objeto de críticas, pero no pretende hacerse cago de ellas: "quienes critiquen dirán hasta dónde se justifica semejante amalgama de la cual no me siento responsable" (11). ¿Quién controla los propios fantasmas? ¿Quién puede decidir cuáles salen y cuáles no? Reyes recrea su experiencia siguiendo simplemente el orden de aparición de sus traumas, sin preocupación alguna por que dicho orden coincida con la realidad de los acontecimientos. Más evidente en su conciencia de ficcionalización es Adolfo Cozzi: "No quise hacer solo una crónica periodística, sino dar a los acontecimientos una dirección y una forma literaria que permitiera captar, transmitir y desentrañar su significación profunda" (Chacabuco 9). No son solo hechos y acontecimientos lo que quiere contar, sino transmitir una experiencia. Para ello, sin ser escritor, sin pretender hacer una obra de ficción, el autor utiliza estrategias narrativas con el fin de lograr, como dice, que el lector "capte" y así se consiga "trasmitir" y "desentrañar" el sentido de la experiencia.

Encontramos, en los testimonios, decisiones de sus autores respecto de la forma literaria que dan a su relato. El testimoniante lleva a cabo un tránsito desde los acontecimientos - su experiencia - hasta un discurso narrativo que busca representarlos. "Este tránsito", dice Hayden White, "se realiza mediante un desplazamiento de los hechos al terreno de las ficciones literarias o, lo que es lo 
mismo, mediante la proyección en los hechos de la estructura de la trama de uno de los géneros de figuración literaria" (Metahistoria 49). El autor, según White, elige entre diferentes "modos de entramado", y la versión y la explicación de los acontecimientos que se generen serán acordes con el modo que escoja ${ }^{15}$. Los acontecimientos, como explica, no son intrínsecamente trágicos o cómicos, "sino que puede[n] constituirse como tal[es] solo en virtud de imponer la estructura de un determinado tipo de relato a los acontecimientos, es la elección del tipo de relato y su imposición lo que dota de significado a estos" (White, El contenido 61). Los autores de los testimonios - ya sea consciente o inconscientementeescogen un tipo de relato, un modo de entramado para proyectar un significado y un sentido.

Es así como, por ejemplo, usando la nomenclatura de White, algunos testimonios adquieren una forma de "romance" en la medida en que buscan marcar la trascendencia del sujeto ante las vicisitudes del mundo y el triunfo del bien sobre el mal. Esto es lo que encontramos, por poner un caso, en los textos que están escritos con una estructura "odiseica": un viaje de ida y regreso al hogar pasando por dolores y penurias, pero que finalmente se resuelve bien en cuanto que se sobrevive y hay un reencuentro con los seres queridos. Algunos incluso tienen la idea del "viaje" en su mismo título, como en el testimonio de Alberto Gamboa, Guillermo Núñez y Sergio Vuskovic (Un viaje). Los mismos exprisioneros hablan expresamente de sus respectivas "odiseas" en los testimonios (Gamboa 21, 24).

El modo de entramado trágico, sin embargo, es el que parece tener más incidencia entre los testimonios. Lo que más se ve en estos es un prisionero que tiene la sensación de ser arrastrado y arrasado sin que pueda hacer nada por impedirlo. En estos testimonios se relata el sistemático empeño por transformar a los prisioneros en simples "objetos", meros "cuerpos"16. Se da cuenta de, al menos, los siguientes órdenes de procedimientos: inmovilización, disciplinamiento, desaparición, profanación, ruptura y destrucción de los cuerpos. Cada una de las acciones tiene finalidades específicas que van desde la venganza, pasando por el sadismo, hasta cuestiones de carácter práctico, como pueden ser la obtención de

15 "Si en el curso de la narración de su relato el historiador le da la estructura de trama de una tragedia, lo ha 'explicado' de una manera; si lo ha estructurado como comedia, lo ha 'explicado' de otra" (White, Metahistoria 18).

16 Hannah Arendt hace ver que en los Lager se experimenta con la vida humana con el objetivo de expulsar todo rasgo de humanidad; a lo que se refiere es a la creación de un sujeto sin reacciones que ella llama "superfluo" (Arendt, Los orígenes; López). Para lograrlo se deben erradicar la pluralidad y la diferencia que existen entre los seres humanos, reduciéndolos a lo mínimo que todos tienen en común, a una igualdad originaria (Arendt, Auschwitz). 
información o el mantenimiento de la disciplina en los centros. Todas ellas, sin embargo, en último término, aunque no sea de modo expreso, están orientadas a conseguir el control o dominio total.

La impotencia es, quizás, la sensación que más se repite en los relatos. Durante la prisión se da siempre la ignorancia acerca de la razón por la que se es tomado como prisionero ${ }^{17}$, la incertidumbre sobre lo que ocurriría en el futuro inmediato $^{18}$, la incapacidad de tomar cualquier decisión sobre cualquier cosa; ni siquiera se puede decidir acerca de las necesidades más básicas. Valdés lo dice claramente: "nos sentimos como conejos de jaula: nuestros amos pueden venir en el momento que quieran para escoger al que quieran y hacer con él lo que se les ocurra" (129-130). Incluso hasta el momento de la liberación está fuera del control de los prisioneros y los sorprende cuando ocurre.

Sea en forma de romance, de tragedia, o cualquier otra, lo cierto es que, como ha dicho Ana María Amar, "los textos ponen en escena una versión con su lógica interna, no son una 'repetición' de lo real sino que constituyen una nueva realidad regida por leyes propias" (447). Dicho en otros términos, el testimonio, lejos de ser un reflejo, una copia de la realidad, configura una interpretación de la misma, crea una representación de la experiencia; de la verdad de las representaciones no es posible hablar. Según afirma adecuadamente Beverley, "no hay un nivel de facticidad social que pueda garantizar la veracidad de una u otra representación. La 'sociedad' misma no es una esencia previa a su representación discursiva, sino precisamente el resultado de luchas para representar y sobre la representación" ("El testimonio" 492). Bustos da una clave cuando señala que "ni la memoria es fiel reproductora de la realidad pasada, ni el olvido constituye una falla o error" (13).

6. Concluyendo ahora, diremos que se ha puesto de manifiesto, en primer lugar, que dado su claro y expreso sentido instrumental, los testimonios tienen siempre un cierto interés que se exhibe expresamente y que sirve como criterio que explica y justifica lo que se dice o se calla, cómo se lo dice, dónde se lo enuncia. La ausencia de acontecimientos, los silencios, incluso la alteración de ciertos órdenes, lo que se destaca o exagera, etc., son algo propio de cualquier relato de acontecimiento, especialmente cuando se busca provocar un efecto. No

17 "Nadie sabe exactamente por qué ha sido detenido. Cada cual tiene sus suposiciones, sus sospechas, pero nadie se considera sorprendido en ningún delito" (Valdés 54).

18 "Como tantas otras veces, íbamos en la oscuridad, sin saber nada, sin poder prever. Igual que cuando nos sacaban del barracón con los ojos vendados, a gritos, para terminar recibiendo una carta o un paquete en el polígono, siempre en la incertidumbre" (Quijada 157). 
tiene nada de extraño, entonces, que en los relatos testimoniales no exista una coincidencia exacta con los sucesos tal como se dan, pues, de hecho, ni siquiera es la pretensión de los autores que se dé siempre dicha coincidencia.

Se ha establecido, además, que el autor de un testimonio no es un verdadero "autor" en el sentido de "autor de una obra literaria", sino una subjetividad desatada en una narración que es expresamente una versión "personal" de lo acontecido. Se trata de un autor que se identifica con el personaje, que es el sujeto de la narración y que, por lo mismo, sigue viviendo, debe seguir haciéndolo, entendiendo que dicha vida, a su vez, afecta la narración misma. No tiene sentido, por lo tanto, plantear la pregunta por su verdad, pues en los testimonios el acercamiento a los sucesos es "personal", y el objeto del relato testimonial no son los hechos, menos aún su secuencia ni su exactitud. Los propios testimoniantes reconocen que sería imposible pretenderlo. Lo que se relata es el sentido de la experiencia; se ponen de manifiesto los sentimientos, las emociones. De lo que se da cuenta en un testimonio de prisión política es del horror, no de los detalles de cada lugar y acontecimiento.

Se decía, finalmente, que en los testimonios, aunque no hay invención de personajes, en el sentido de "ficciones", pues el protagonista de la historia, el de la experiencia y el autor se funden, tiene lugar una expresa y declarada ficcionalización y narrativización de la realidad. El autor produce un relato en el que se plasma una versión ficcionalizada de la experiencia vivida. La condición productiva y no meramente reproductiva de estos relatos es algo que sus mismos autores tienen claro. Para ello, sin ser escritores, ni pretender hacer una obra de ficción, el autor utiliza estrategias narrativas para lograr que el lector capte el sentido de la experiencia. Lo que se relata, entonces, es una versión con su propia lógica interna y, por lo tanto, es inconducente hablar de error, equivocación o falsedad si el testimonio no coincide con los hechos concretos.

Con estas aclaraciones se ha buscado poner en evidencia algunas razones por las cuales no tendría sentido desestimar los testimonios a causa de su nocoincidencia con la realidad de los hechos, señalar que la información contenida en ellos es "falsa". En los testimonios, dadas sus características especiales, en realidad no se plantea una dicotomía entre ficción y realidad, y, por lo tanto, no corresponde invalidarlos utilizando como argumento el que no concuerden con los hechos. 


\section{Obras citadas}

Achugar, Hugo. "Notas sobre el discurso testimonial latinoamericano". La historia de la literatura Iberoamericana: memorias del XXVI Congreso del Instituto Internacional de Literatura Iberoamericana. Eds. Raquel Chang-Rodríguez y Gabriella de Beer. Hanover, NH: Ediciones del Norte, 1989. 279-294.

Amar Sánchez, Ana María. "La ficción del testimonio". Revista Iberoamericana 151 (1990): 447-462.

Arendt, Hannah. Auschwitz et férusalem. París: Deuxtempes, 1993.

-. Los orígenes del totalitarismo. Madrid: Alianza, 1987.

Beverley,John. "Anatomía del testimonio". Revista de Crítica Literaria Latinoamericana 25 (1987): 7-16.

-. "The Margin at the Center: On Testimonio (Testimonial Narrative)". Modern Fiction Studies 35 (1989): 11-28.

-. "Subalternidad y testimonio. En diálogo con Me llamo Rigoberta Menchú y así me nació la conciencia, de Elizabeth Burgos". Nueva Sociedad 238 (2012): 102-113.

—. "El testimonio en la encrucijada". Revista Iberoamericana 164-165 (1993): 485-495.

Bustos, Guillermo. "La irrupción del testimonio en América Latina: intersecciones entre historia y memoria. Presentación del dossier 'Memoria, historia y testimonio en América Latina"'. Historia Crítica 40 (2010): 10-19.

Certeau, Michel de. La escritura de la historia. México: Universidad Iberoamericana, 2000.

Concha, Jaime. "Testimonios de lucha antifascista". Araucaria de Chile 4 (1878): 129-146.

Dorfman, Ariel. "Código político y código literario: el género testimonio en Chile hoy". Jara y Vidal 170-234.

Duchesne, Juan Ramón. "Miguel Barnet y el testimonio como humanismo". Revista de Crítica Literaria Latinoamericana 26 (1987): 155-160.

Epple, Juan Armando. "Acercamiento a la literatura testimonial en Chile". Revista Iberoamericana 168-169 (1995): 1143-1159.

García V., Gustavo. "Hacia una conceptualización de la escritura de testimonio". Revista Canadiense de Estudios Hispánicos 25.3 (2001): 425-444.

Gómez Chávez,José. "Génesis y desarrollo del testimonio latinoamericanao contemporáneo". Memoria del XIX Coloquio de literatura Mexicana e Hispanoamericana. Sonora: Universidad de Sonora, 2005. 53-63.

Guzmán, Nancy. Romo: confesiones de un torturador. Santiago de Chile: Planeta, 2000. Jara, René. "Prólogo: testimonio y literatura". Jara y Vidal 1-6.

Jara, René y Hernán Vidal, eds. Testimonio y literatura. Minneapolis: Insitute for the Study of Ideologies and Literatures, 1986.

Le Goff, Jacques. Pensar la historia. Madrid: Altaya, 1995. 
López, María José. "Campos de concentración: el horror de los cuerpos superfluos según Hannah Arendt". Revista Perspectivas Éticas 18 (2007): 7-36.

Montealegre, Jorge. Memorias eclipsadas. Duelo y resiliencia comunitaria en la prisión política. Santiago de Chile: Asterión, 2013.

Portelli, Alessandro. La orden y a fue ejecutada. Buenos Aires: FCE, 2004.

Sklodowska, Elzbieta. "Hacia una bibliografía sobre el testimonio latinoamericano". Chasqui 20-21 (1991): 108-118.

-. Testimonio hispano-americano. Historia, teoría, poética. Nueva York: Peter Lang, 1992.

-. "Testimonio mediatizado: iventriloquía o heteroglosa? Barnet/Montejo; Burgos/ Menchú". Revista de Crítica Literaria Latinoamericana 38 (1993): 81-90.

Strejilevich, Nora. El arte de no olvidar. Literatura testimonial en Chile, Argentina y Uruguay en los 80 y 90. Buenos Aires: Catálogos, 2005.

Villoro, Luis. "El sentido de la historia". Historia ipara qué?. México: Siglo XXI, 1980. 33-52.

White, Hayden. El contenido de la forma. Barcelona: Paidós, 1992.

-. Metahistoria. La imaginación histórica en la Europa del siglo XIX. México: FCE, 1992.

Yúdice, George. "Testimonio and Posmodernism". Latin America Perspectives 18.3 (1991): 15-13.

-. "Testimonio y concientización". Revista de Crítica Literaria Latinoamericana 36 (1991): 207-227. También en La voz del otro: testimonio, subalternidad y verdad narrativa. Eds. John Beverley y Hugo Achugar. Berkeley; Lima: Latinoamericana, 1992.

\section{Testimonios}

Ahumada, Manuel. Testimonio: Cerro Chena, un campo de prisioneros. Santiago de Chile: Leonardo Sepúlveda Producciones Gráficas, 2003-2011.

Alonso Oyanedel, Freddy. La verdad de Pisagua: 19731974. Iquique: Colección Campus UAP, 2004.

Álvarez, Rolando. Papá no va a llegar porque está trabajando en el norte. Memorias y epistolario de un preso político comunista y su familia en Chile. Santiago de Chile: Isadora Stuven; LOM, 2012.

Amorós, Mario. La memoria rebelde. Testimonios sobre el exterminio del MIR.

De Pisagua a Malloco 1973-1975. Santiago de Chile: Escaparate, 2008.

Arce, Luz. El infierno. Santiago de Chile: Planeta, 1993.

Aylwin, Andrés. Simplemente lo que vi. Santiago de Chile: LOM, 2003. 
Becker, Nubia (Carmen Rojas). Recuerdos de una mirista. Santiago de

Chile: Ediciones del Taller, 1987. Publicado nuevamente bajo el nombre Una mujer en Villa Grimaldi. Santiago de Chile: Pehuén, 2011.

Benavente, Mario. Contar para saber: Chacabuco, Puchuncaví, Tres Álamos (1973-1975). Santiago de Chile: J y C Producciones Gráficas, 2003.

Bitar, Sergio. Isla 10. Santiago de Chile: Pehuén, 1987.

Bonnefoy, Pascale. Terrorismo de estadio. Prisioneros de guerra en un campo de deportes. Santiago de Chile: Chile América; CESOC, 2005.

Carmona, Ernesto. Morir es la noticia. Santiago de Chile: Ernesto Carmona, 1997.

Carrasco, Rolando. Prigué. Santiago de Chile: Aquí y Ahora, 1991. Moscú: Novosti, 1977.

Casassus, Juan. Camino en la oscuridad. Santiago de Chile: Debate, 2013.

Cerda, Carlos, ed. Chacabuco voces en el desierto. Santiago de Chile: Pehuén, 1994.

-.Pan de pascua. Weihachsbrot: Aufbau, 1978.

Corvalán, Luis Alberto. Viví para contarlo. Santiago de Chile: Tierra

Mía, 2007. Publicado originalmente bajo el título de Escribo sobre el

dolor y esperanza de mis hermanos. Praga: Sofia Press, 1976.

Cozzi, Adolfo. Chacabuco, Pabellón 18, casa 89. Santiago de Chile: Sudamericana, 2002.

-. Estadio Nacional. Santiago de Chile: Sudamericana, 2000.

Durán, Claudio. Autobiografía de un exjugador de ajedrez. Santiago de Chile: LOM, 2003.

Figueroa, Virgilio. Testimonio sufrido. Santiago de Chile: Comala, 1979-1991.

Gamboa, Alberto. Viaje al infierno. Santiago de Chile:

Forja, 2010. Santiago: Araucaria, 1984 .

García,Juan Carlos. Crimen sin castigo, Valdivia, Neltume, Santiago Tejas

Verdes. Santiago de Chile: Mosquito Comunicaciones, 2004.

González, Ruth. La pérdida de Paz Rodríguez. Santiago de

Chile: Mosquito, 1991. Colección Testimonio.

Guerrero, Manuel. Desde el túnel, diario de vida de un detenido

desaparecido. Santiago de Chile: LOM, 2008.

Jenkin, Enrique. Exijo una explicación. Mis secuelas de una dictadura.

Santiago de Chile: José Antonio Mendizábal, 2010.

Joui Joui, Sadi Renato. Chacabuco y otros lugares de detención.

Santiago de Chile; Valparaíso: autoedición, 1994-2003.

Lawner, Miguel. Retorno a Dawson. Santiago de Chile: LOM, 2004 .

Lira, Carlos. Der Gefangene Gefangnis direktor: 26 Monate erlebter

Faschismus in Chile. Hamburg: Verlag Atelier im Bauemhaus, 1977.

Merino, Marcia (Flaca Alejandra). Mi verdad: más allá del

horror, yo acuso. Santiago de Chile: ATGSA, 1993. 
Montealegre, Jorge. Frazadas del Estadio Nacional. Santiago de Chile: LOM, 2003.

Montes, Jorge. La luz entre las sombras. Santiago de Chile: Comala, $1992 a$.

-. Los días aciagos. Concepción: LAR, 1992b.

Núñez, Guillermo. Diario de viaje. París: Instituto Chileno-Francés de Cultura, 1979.

Parra, Ángel. Manos en la nuca. Madrid: Tabla Rasa, 2005.

Quijada, Aníbal. Cerco de púas. 1977. Santiago de Chile: Fuego y Tierra, 1990.

Quinteros, Haroldo. Diario de un preso político chileno.

Madrid: Ediciones de la Torre, 1979.

Reyes, Francisco. Testigo presencial, tragedias humanas de un Chile fascista. 1981. 8. ${ }^{\text {a }}$ ed. Quito: 4 de Septiembre, 2000.

Rivas, Patricio. Chile, un largo septiembre. Santiago de Chile: LOM, 2007.

Rodríguez Freire, Raúl. "Literatura y poder: sobre la potencia del testimonio en América Latina". Atenea 501 (primer semestre de 2010): 113-126.

Valdés, Hernán. Tejas verdes: diario de un campo de concentración en Chile. Barcelona: Ariel; Laia, 1996.

Valle, Juan del. Campos de concentración, Chile 19731976. Santiago de Chile: Mosquito, 1977.

Villegas, Sergio. Chile, el estadio, los crímenes de la funta Militar. Buenos Aires: Cartago, 1974.

Vitale, Luis. La vida cotidiana en los campos de concentración en Chile. Caracas: Universidad Central de Venezuela, 1979.

Vuskovic, Sergio. Dawson. Madrid: Meridión, 1984.

-. Un viaje muy particular. Comentario. 2006. Publicado en $L a$ Cañada. Revista del Pensamiento Filosófico Chileno 4 (2013).

Witker, Alejandro. Chile; Prisión en Chile. México: FCE, 1975.

Zalaquett, Cherie. Sobrevivir a un fusilamiento. Santiago de Chile: Aguilar; El Mercurio, 2005. 